\title{
Renewal of an entry to practice baccalaureate nursing curriculum: Adapting to complexity
}

\author{
Catherine Mary Fetherston, Caroline Browne, Prue Andrus, Sharryn Batt \\ School of Health Professions, Murdoch University, Perth, Australia
}

Received: September 12, 2017

Accepted: October 13, 2017

Online Published: October 23, 2017

DOI: $10.5430 /$ jnep.v8n2p104

URL: https://doi.org/10.5430/jnep.v8n2p104

\begin{abstract}
Curriculum re-design in entry to practice nursing degrees requires a rigorous and multifaceted approach to align the needs of students, professional and industry stakeholders, community needs, the faculty's vision and university and regulator requirements. This paper relates the initial steps in the process taken to achieve this re-design in one Australian university's Bachelor of Nursing program, and describes our experiences in two parts. The first part outlines the context in which the need for curriculum renewal was triggered and the ensuing processes undertaken in the development of our new course aim, course outcomes and graduate attributes. The second part discusses how undertaking these activities then came to influence the adoption of Complexity Thinking in the design of our conceptual model, which then guided our program structure and overarching learning and teaching approaches. We share these experiences to illustrate the steps we undertook on this journey, to outline and example the program we created, and to continue the scholarly discussions around the design of baccalaureate nursing program structures, especially those that implement pedagogies inspired by the concepts related to Complexity Theory. The choice of complexity thinking as a guiding theory was key in providing the lens through which we were inspired to graduate nurses with the skills to provide care in complex situations and value the learning that comes through uncertainty, reflection, adaptation and emergence.
\end{abstract}

Key Words: Curriculum, Re-design, Renewal, Nursing, Complexity

\section{INTRODUCTION}

Nurses work in increasingly varied and complex environments creating significant challenges for educators when designing and delivering entry to practice curricula. This is particularly so as nursing faculties worldwide continually strive to introduce contemporary pedagogies that deliver the course and learning outcomes that will meet not only the evolving needs of their students, but also those of the community, industry, university and accrediting bodies. This is by no means a new challenge as faculties have long engaged in the process of continuous review and change to ensure on-going rigor and quality of their programs. However at certain points in the life of a curriculum something more than incremental change is necessary to ensure a whole of program approach to meeting those outcomes, and as a result renewal and re-design of that curriculum is required. The realization of this need occurred for our faculty over time as we collected feedback from students, academics, consumers and industry during the life of the then curriculum. As a result of that feedback it was deemed important for us to work together to develop a more contemporary conceptual model that could influence and give voice to a program that would allow the expression of what we believed it was that our students needed to be able to achieve upon graduation.

\footnotetext{
*Correspondence: Catherine Mary Fetherston; Email: C.Fetherston@murdoch.edu.au; Address: School of Health Professions, Murdoch University, Perth, Australia.
} 
This paper shares with readers our experiences in two parts. The first part outlines the context in which the need for curriculum renewal was triggered and the ensuing processes undertaken in the development of our new course aim, course outcomes and graduate attributes. The second part discusses how undertaking these activities then came to influence the adoption of Complexity Thinking ${ }^{[1]}$ in the design of our conceptual model, which then guided our program structure and learning and teaching approaches. We share these experiences to illustrate the steps we undertook on this journey, to outline and example the program we created, and to continue the scholarly discussions around design of baccalaureate nursing program structures, ${ }^{[2,3]}$ especially those associated pedagogies inspired by the concepts related to Complexity Theory. ${ }^{[4]}$ Although couched within an Australian setting we believe there will be many commonalties with nursing education providers in other countries where faculties are seeking to renew their curricula to meet healthcare needs in what has become a very complex and challenging world in which to provide nursing care.

\section{Curriculum Re-Design processes}

A range of considerations drive the content and teaching and learning aspects of curricula in entry to practice nursing programs. These include but are not limited to: political, social, environmental and economic factors, as well as technological and theoretical advances and professional and industry expectations. ${ }^{[5,6]}$ Layered within these considerations is the need to ensure the provision of outcomes related to quality care and safety, and healthcare reform, ${ }^{[7]}$ all delivered through innovative and contemporary pedagogies. In Australia, and many other countries, these outcomes are assured through university and professional accreditation processes undertaken by an independent accreditation council or body. ${ }^{[8]}$ Accreditation not only ensures programs meet a recognized standard but also provide impetus for education providers to review and revise their programs on a regular basis. It was in preparation for our most recent accreditation review that our faculty determined that if we were to ensure a holistic approach to contemporary program delivery and outcomes, incremental quality improvements had now reached their limit and a re-design of the curriculum was required.

The re-design process to be outlined was led by a project team comprised of members leading, and teaching into, the existing Bachelor of Nursing program. The project team consisted of the discipline head and then associate dean of learning \& teaching $(\mathrm{CF})$, the then program academic chair (CB), the simulated learning lead (PA) and a course lecturer (SB), all of whom had been involved in the existing program over a number of years. This make-up ensured a diversity of

Published by Sciedu Press skills and a broad representation of expertise in key content and policy areas and was complemented by ongoing consultation with relevant teaching staff (faculty) and community and institutional stakeholders, at all major steps in the re-design.

Curriculum renewal has been described by Lachiver and Tardif ${ }^{[9]}$ as requiring a number of steps to ensure a robust and comprehensive design process. These steps include: analysis of the current offerings and context; formulation of key program aims; prioritization of resources and development strategies; implementation of the targeted curricula change; and establishment of monitoring tools and processes. This paper reports specifically on the stages related to contextual analysis, formulation of key aims and outcomes and prioritization of development strategies and approaches. The first step, contextual analysis, involved an examination of the contextual factors influencing contemporary professional and community expectations of graduates followed by a decision on how these expectations should be reflected. This step resulted in the development of a new course aim, learning outcomes and graduate attributes, which then influenced the choice of a theoretical framework to guide how the re-design was conceptualized and implemented. The resulting conceptual model was viewed as fundamental in providing a lens to the pedagogical approaches and teaching strategies that could best achieve the program aim, course outcomes and graduate attributes. As the development phase progressed, course content and assessments were then scaffolded in such a way that best met the wide range of complex demands being considered.

A working curriculum document was formulated prior to the implementation stage to record the process and the outcomes. This document enabled the display of a coherent representation of how course aims, conceptual framework and desired outcomes were inexorably linked to the final structure and quality of the education program to be adopted. This design process was an iterative one and continues, even during implementation, as a result of ongoing evaluation. These initial steps in our journey proved to be essential in providing the basis on which successful implementation could occur, and are now described in more detail.

\section{RESPONDING TO CONTEXTUAL FACTORS DRIVING CHANGE}

A strong curriculum that meets the community's needs requires the buy-in of those directly involved. ${ }^{[10]}$ As a consequence, during the initial step of the process, extensive feedback was sought from a range of stakeholders to review the strengths and weaknesses of the current program, seek suggestions for future changes and develop a greater un- 
derstanding of the healthcare environments our graduating students would engage with.

\subsection{Stakeholder buy-in}

Stakeholders included current students, graduates, academics teaching into the existing program, health consumers, collaborators and a university curriculum expert. Consumers and collaborators consisted of representatives from local private and public health care facilities and consumer groups, and clinical education providers across the spectrum of acute care, community health, Indigenous health and aged care. Feedback was sought by the project team through a variety of means including surveys, focus groups and individual meetings. A brief summary of the main strengths of the existing program and key suggestions for change are presented in Table 1. This feedback then contributed to the direction of a series of curriculum planning meetings between the project team and faculty to outline a plan as how best to incorporate the suggestions for change into the revision of the program.

Table 1. Summary of feedback from internal and external stakeholders

\begin{tabular}{|c|c|c|}
\hline & Strengths of the curriculum under review & Suggested areas for improvement \\
\hline $\begin{array}{l}\text { Internal } \\
\text { stakeholders }\end{array}$ & $\begin{array}{l}\text { Program is student centered and has progressive } \\
\text { knowledge development with a strong emphasis } \\
\text { on nursing values and professional standards } \\
\text { (academics). } \\
\text { Program encourages a strong sense of } \\
\text { community and belonging and lecturers are } \\
\text { approachable (students). } \\
\text { Highlights: capstone unit, simulation scenarios, } \\
\text { skills and clinical practice (students). }\end{array}$ & $\begin{array}{l}\text { Remove repeated content between units. Replace silo content } \\
\text { based approach to avoid “dumping of knowledge”. } \\
\text { Integrate theory \& practice more effectively. } \\
\text { Provide skills training specific to clinical area immediately prior } \\
\text { to placement to optimize experience. } \\
\text { Scaffold content in an A to E approach } \\
\text { Insert research skills earlier in the course. }\end{array}$ \\
\hline $\begin{array}{l}\text { External } \\
\text { stakeholders }\end{array}$ & $\begin{array}{l}\text { Students on placement demonstrate a good } \\
\text { knowledge base, are enthusiastic, organized, } \\
\text { research confident \& ethically aware. Also } \\
\text { knowledgeable regarding assessment } \\
\text { requirements \& documentation \& aware of } \\
\text { organizational policies. } \\
\text { Strong stakeholder partnerships exist. }\end{array}$ & $\begin{array}{l}\text { Encourage enthusiasm for the lesser "rock star” status areas such } \\
\text { as aged care. } \\
\text { Provide skills to increase confidence on graduation. } \\
\text { Provide skills for competent management of complex and } \\
\text { changing situations. } \\
\text { Encourage more realistic expectations related to job placements } \\
\text { on graduation (i.e., not everyone can work in A\&E). } \\
\text { Implement more even spread of 3rd year clinical placements. }\end{array}$ \\
\hline
\end{tabular}

\subsection{Health and professional influences}

Stakeholder feedback was complemented by an extensive literature review. The literature sought related to responding and being accountable to international professional expectations, university and professional governance and accreditation requirements, current national and local health priorities, health reform and health workforce needs. This examination, in conjunction with stakeholder feedback guided the direction for the new curriculum's content and subsequent development of the overarching course aim.

One of the major influences identified from the review of the literature was the health challenges facing our local communities. These challenges are identified by the Council of Australian Governments (CoAG) $)^{[11]}$ and are not dissimilar to the challenges being experienced by developed countries globally. ${ }^{[12]}$ They include an aging population, high levels of chronic disease, an increasingly dispersed population with a number of localities of higher than average socio economic disadvantage, an aging workforce, workforce shortages and a high Indigenous population with significantly poorer health outcomes than the general population. On a national level, there are also a number of Health Priority Areas that have been identified within the framework of Australia's National Chronic Disease Strategy. ${ }^{[13]}$ As a result, it was clear that in preparing future graduates to address both local and national challenges, these content areas would need emphasis in the new curriculum.

Other literature of interest comprised key position statements, national reports and professional standards. Examples of these included, from an international perspective, the International Council of Nurses' (ICN) position statements in relation to nursing roles, the nursing profession, socioeconomic welfare of nurses, health care systems and social issues. Nationally, the curriculum drew on the Nursing and Midwifery Board of Australia (NMBA) policies, codes and guidelines, specifically those related to the registered nurse, such as our national Registered Nurse Standards for Practice, ${ }^{[14]}$ as well as the National Safety and Quality Health 
Service (NSQHS) standards ${ }^{[7]}$ and relevant national and state legislation.

\subsection{Local university considerations}

Any university program also needs to accord with the overall vision, priorities and educational principles of their university. Our university's overarching values and the core priorities supporting these values, along with curriculum policy and guidelines on the core characteristics, curriculum elements and structures of undergraduate degrees formed the scaffolding for the structural aspects of the program re-design. ${ }^{[15]}$ The core characteristics and elements required that degrees incorporate foundational skills for transition to university, evidence based major units increasing in depth and sophistication across the three years, alongside a sequence of interdisciplinary breadth and research studies. Therefore it was essential that these principles, combined with the contextual factors identified, formed the guiding basis of the structural aspect of our intended curriculum.

\section{DeVelopment of a COURSE Aim, OUTCOMES AND GRADUATE NURSE ATTRIBUTES}

\subsection{Course aim}

Construction of the course aim emerged following an indepth examination of all aforementioned contextual considerations. An iterative process was undertaken where ideas were discussed amongst stakeholder focus groups and academic curriculum working parties and once all contributors expressed approval, the course aim for the re-designed Bachelor of Nursing program was decided upon as in Figure 1.
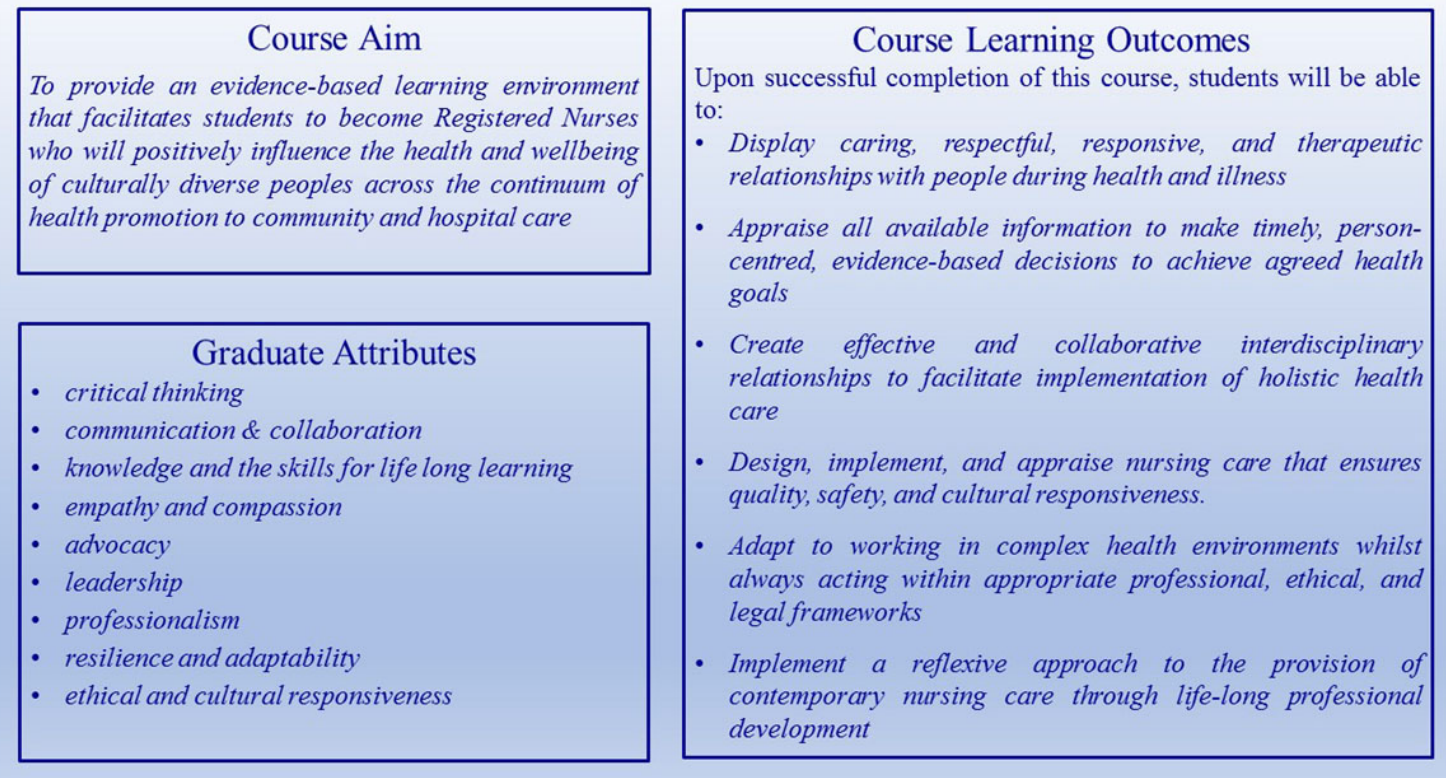

Figure 1. Bachelor of Nursing course aim, course outcomes and graduate attributes

\subsection{Graduate nurse attributes}

Once the course aim was agreed to it was then important to identify graduate nurse attributes and course level learning outcomes. The learning outcomes and attributes were developed in tandem, also using an iterative process that included brainstorming meetings with academics and facilitators from our university centre for teaching and learning. More specifically, the graduate nurse attributes were developed by distinguishing those considered specific to Nursing but not currently identified within the university graduate attributes; ${ }^{[16]}$ and then the two were rationalized and combined. Nine graduate nurse attributes emerged (see Figure 1).

\subsection{Course outcomes}

A range of considerations influenced the development of the course outcomes. The University's curriculum principles provided the structural framework ${ }^{[15]}$ and the final learning outcomes were informed by, adapted from, and mapped to our national nursing board's Standards for Practice ${ }^{[14]}$ with alignment to our new Graduate Nurse Attributes. Our course outcomes were designed to define the knowledge, skills and applications that could be expected from a graduate of our new curriculum, and were primarily guided by our national Standards for Practice ${ }^{[14]}$ and the need for graduate nurses to be able to: think critically, reflect and adapt to changing knowledge through life long learning; practice nursing within 
a legislative, professional and ethical framework; provide safe, therapeutic and culturally responsive nursing care in collaboration with other health professionals, and adopt personal, professional and social responsibility for their nursing practice. A visual representation of the relationships between the course aim, the course outcomes and the graduate attributes is given in Figure 1.

\section{DEVELOPING A GUIDING CONCEPTUAL MODEL}

Once the course aim, course outcomes and graduate nurse attributes had been identified by faculty the next step was to either adopt or design a framework that would reflect these concepts and assist to guide the content structure and pedagogical approaches of the new curriculum. It was the contextual analysis and development of the course outcomes and graduate attributes that highlighted for faculty the complex array of factors that required consideration in the development of a new program. This, combined with the ever increasing complexity of the role of the nurse and their need to be continually adapting to changes in those complexities, led us to explore Complexity Theory to assist with the conceptualization and design of the new curriculum. ${ }^{[17]}$

\subsection{Complexity theory and its application to health and education}

It is now more than 15 years since the challenges related to the complexity of health care provision were discussed in a series of four papers published in the British Medical Journal. ${ }^{[18-21]}$ It was concluded in the introductory article by Plesk \& Greenhalgh ${ }^{[18]}$ that "to cope with [escalating complexity] we must abandon linear models, accept unpredictability, respect (and utilise) autonomy and creativity, and respond flexibly to emerging patterns and opportunities" (p.628). In the intervening years since these publications similar commentary and discussions began to emerge in the form of edited works such as Lindberg, Nash and Lindberg's 2008 'On the Edge: Nursing in the Age of Complexity' [22] and in the discipline of education: Doll and colleague's 2005 and revised 2008 'Chaos, Complexity, Curriculum and Culture', ${ }^{[23]}$ and Mason's 2008 'Complexity Theory and the Philosophy of Education'. [1] These and other conversations ignited some opposition to the use of what was argued to be the misguided appropriation and psychologising of complexity theory in its application to health care. ${ }^{[24,25]}$ Despite this opposition the concepts and metaphors drawn from this theory clearly continue to help people to make sense of the healthcare environment in which they work and inspire them to think creatively about approaches to managing the complex problems they encounter. ${ }^{[18]}$ This can be seen in a range of areas where 'complexity thinking' continues to inspire change and innovation in curricula across a variety of health disciplines such as, for example, medicine, ${ }^{[26]}$ healthcare management, ${ }^{[27]}$ dentistry, ${ }^{[28]}$ sports science, ${ }^{[29]}$ interprofessional practice ${ }^{[30]}$ and nursing. ${ }^{[31]}$

Complexity Theory has been proposed as "a natural framework for nursing educators and nurse leaders to use in ... solving complex, unpredictable problems in highly complex organizations and evolving health care systems" ${ }^{[32]}$ (p.137). The evolution of complexity theory is in itself multifaceted with broad reaching links to general systems theory, cybernetics, system dynamics ${ }^{[33]}$ and chaos theory. ${ }^{[34]}$ Complexity theory challenges previously accepted beliefs that reductionism and linear models of cause and outcome, which are associated with a sense of order and structure and have a predictable result, are either the only, or the best way, to find solutions to problems. "Complexity theory invites us to consider the interrelationships of the emotional, psychological, spiritual, cultural, social, and other patterns influencing each being's reality at any given point in time",; ${ }^{[34]}$ and in doing so acknowledges that the results of these inter-relationships are not always predictable. Even within a complex macrosystem such as Nursing, which has a recognized focus and associated processes, there are many microsystems with varied and changing components that dynamically interact in different ways. These interactions continue to evolve over time and even small changes within a system may easily result in unpredictable and disordered outcomes. Complexity theory recognizes this eventuality and proposes that elements (and people) within any system will interact and adapt to those interactions, and their outcomes, through a complex adaptive system that enables the attainment of a specific goal. ${ }^{[1]}$ Broadly, in nursing that goal is the "caring support of a client with health care needs". ${ }^{[34]}$ This goal can be achieved in many and varied ways depending on the inter-relationships between, client, family, community, health professionals and the health care system. Consequently it is the conceptual underpinnings generated by considering responses to complexity that enable us to recognize how emergent learning and adaptation by all system elements in a changing environment is important to achieve a desired health related goal.

"We can understand many parts of the universe in (reductionist) ways but the larger and more intricately related phenomena can only be understood by principles and patterns-not in detail. Complexity deals with the nature of emergence, innovation, learning and adaptation" ${ }^{[35]}$ (p.294)

\subsection{Nursing in a complex world}

The notion of complex adaptive systems and emergent learning has significant application in nursing and nurse education 
contexts, particularly where the importance of holistic nursing and being responsive, or adaptive, to changing situations is well recognized. Further to this, Morrison, ${ }^{[17]}$ in relation to education philosophy, suggests the human mind is itself a complex adaptive system challenging the oft-accepted approach that the mind is an empty vessel primed to receive whatever knowledge might be poured into it. In recognition of the concepts underlying complexity theory and complex adaptive systems we established that out curriculum framework should be guided by an overarching concept that would assist students to recognize and be constantly reminded of the context of change, unpredictability and complexity, and thus we settled on the label Nursing in a Complex World. Within this overarching concept we brought together a number of other contextual elements, previously discussed, to assist in forming the conceptual model for our curriculum.

Central to our model is that specific characteristic that embodies the goal that as nurses we strive to attain, and that is the Caring, Therapeutic Relationship. As a faculty we believed it was essential to write a curriculum that has the capacity to support nursing students to prepare for the many complex contextual components they will encounter and the varied outcomes that can result when trying to build that relationship. Following discussion within working groups the Nursing faculty felt these components were best represented by the program content domains of: People in Health and Illness and Holistic Evidence Based Nursing Care. The intersect created by the learning that occurs in these specific domains facilitates the building of the central element or goal, which is the Caring Therapeutic Relationship (see Figure 2).

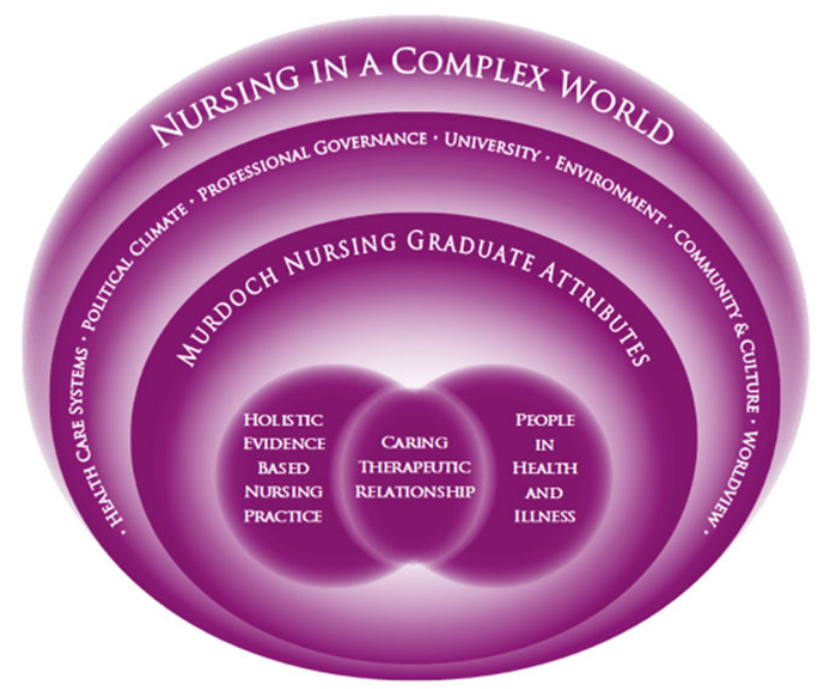

Figure 2. Program conceptual model: Nursing in a Complex World

The contextual complexities in which nursing students learn Published by Sciedu Press about these domains, and in which graduate nurses practice, include a range of personal and environmental factors. Rather than represent each of the factors within nested systems in the model we have combined the concepts that reflect these factors and identified them graphically within the circles that influence the content domains of our nursing curriculum (see Figure 2). These are the boundaries imposed or influenced by university, environment, health care systems, political climate, professional governance, community and culture, and worldview, and these factors form the outer circle in the framework. This outer circle, or environment, provides context within which the curriculum will facilitate the program's desired graduate nurse attributes. These attributes are contained within the adjacent circle and include knowledge and life-long learning, critical thinking, ethical and cultural responsiveness, leadership, professionalism, advocacy, communication and collaboration, resilience and adaptability, and empathy and compassion. Environmental contextual factors and the graduate nurse attributes strongly influence the development of the content within the curriculum's content domains of People in Health and Illness and Holistic Evidence Based Nursing Care, providing a structural framework where adaptation and emergence can occur in relation to both learning and teaching. Using our newly designed conceptual model we then sought a pedagogical approach that would generate the desired outcomes from our new curriculum

\section{ADOPTING COMPLEXITY ORIENTED PEDAGOGICAL APPROACHES}

Numerous pedagogical approaches exist, grounded in a range of educational theories such as behaviouralism ${ }^{[36]}$ and more recently androgogy, ${ }^{[37]}$ constructivism, ${ }^{[38]}$ student centered learning ${ }^{[39]}$ and reflective practice; ${ }^{[40]}$ and there is merit in adopting all or any according to the outcomes being sought. However we felt it was important in our re-design to adopt a teaching approach that would align to our conceptual model and provide consistency in (and underpin) our desire to develop in students the ability to interact, reflect, learn and adapt, no matter what the context they found themselves in. Adopting a complexity oriented learning approach was seen by us as providing the capacity to recognize the value of all of the aforementioned pedagogies whilst also considering the basic tenets of "change, evolution, adaption and development" achieved through our relationships with others and the external world ${ }^{[17]}$ (p.19). Relationships with students are the key, and teachers are described as needing to:

"Move from the role as an expert and transmitter to a facilitator, co-learner and co-constructor of meaning, enabling learners to connect new knowledge to existing knowledge. Learners for 
their part have to be prepared to exercise autonomy, responsibility, ownership, self direction and reflection... the curriculum and learning bind cool reflection with passion and humanity. . . in complexity theory, learning becomes a joint voyage of exploration, not simply of recycling given knowledge". [17]

With this in mind we sought an overarching pedagogy that would reflect the complexity approach to learning, and emphasize the relationships between learner and teacher, learner and knowledge, and between knowledge and knowledge development, thus providing opportunities for graduates to learn the skills necessary to continually interact with, reflect on, and adapt to, complex and changing situations and workplaces. This aim led us to adopt a focus on case based inquiry supported by a simulated learning environment and work integrated learning embedded across our content domains of People in Health and Illness and Holistic Evidence Based Nursing Care.

\subsection{Adapting to complexity through case based inquiry}

Case based inquiry (CBI) is similar to the more commonly known problem based learning (PBL) except that CBI differs in so much as it requires students to have a certain amount of knowledge that assists and guides them in solving the problem at hand, whilst also encouraging students to develop a collaborative team based approach to their learning. ${ }^{[1]}$ By using industry relevant case studies, this form of teaching provides students with the opportunity to consolidate their critical thinking skills and confidence, whilst developing knowledge and clinical skills in a collaborative environment to assist in their transition to clinical practice. CBI aims to prepare students for clinical practice by linking theory with practice and by encouraging students to apply their knowledge in authentic case studies. ${ }^{[42]}$ By its nature, complexity theory asks us to view nursing care as a dynamic and multifaceted process that requires a nurse to have the skills to anticipate, analyze, interact and adapt within a variety of complex systems. ${ }^{[32]} \mathrm{CBI}$ provides a process through which we can effectively prepare our nursing students to meet this challenge. This pedagogical approach moves the student from knowledge retention to the application of knowledge which allows them to assign meaning to each case study. ${ }^{[43]}$ Students are guided through the inquiry process to meet both predefined and individually constructed learning outcomes to consolidate the integration of theoretical knowledge into holistic practice.

CBI in nursing reflects many of the key aspects of a complexity based pedagogy, as can be seen by the following description, which also has many shared concepts with those outlined above by Morrison, ${ }^{[17]}$ when he discusses the roles of teachers and learners as seen through the eyes of complexity theory.

"(CBI is) an orientation towards learning that is flexible and open and draws upon the varied skills and resources of faculty and students. Faculty are co-learners who guide and facilitate the student-driven learning experience to achieve the goals of nursing practice. This includes an inter-disciplinary approach to learning and problem-solving, critical thinking and assumption of responsibility by students for their own learning." ${ }^{[44]}$ (p.146)

Subsequently, all case inquiries embedded across the program have been planned to begin with a question that allows students to explore the intertwining domains of the individual, society, disease and wellbeing, within a nursing context. ${ }^{[45]}$ Students undertake this inquiry within groups where they are provided the freedom, over several weeks, to plan their own learning, whilst also having to adapt to working alongside other group members with the aim of reaching a common goal through self organization; the goal being a therapeutic caring relationship with the person who is the subject of their case. In our new program the beginning knowledge and resources that enable students to explore the cases is provided in both their foundation year and in associated theoretical and skills' units scaffolded through the second and third years of the degree. This use of CBI as a pedagogical underpinning was planned so as to encourage students to experience complexity and uncertainty within the cases they explored and within the adaptive relationships they developed with their fellow students as they worked alongside one another to achieve their goal, and where there could potentially be a diversity of solutions that could then be shared amongst groups. We felt this fitted in well with Mitchell and colleague's ${ }^{\text {[4] }}$ description of complexity based curricula activities, which are designed to: "enable students to be directors of their own learning paths within the confines of relevant course concepts; [allow them to] benefit from a diversity of views and the plurality of truths, and to invite learning in community through dialogue, an inquiry of difference and critical thinking" (p.34). The emergent learning that can potentially occur from this process married well with the program's conceptual model and the increasingly complex nature of health care demands and patient interactions that future nursing students and graduates will be presented with once they apply their learning in the workplace. 


\subsection{Adapting to complexity through simulation and} workplace integrated learning (WIL)

The consolidation and application of learning through workplace clinical practice is both the cornerstone and the capstone of all pre-registration nursing programs. It provides the strongest opportunity for students to experience authentic and integrative learning in an interdisciplinary and complex environment and is consistently the area that students commented on as being the most valuable in our then unit and course evaluations. Despite this, it has been recognized for some time that the already over burdened health system's capacity to fulfill student placements is facing a crisis, ${ }^{[46]}$ at least within our country, with demand for student clinical placements growing from 2011 to 2012 by $8.4 \%$, or 2.7 million hours. ${ }^{[47]}$ Added to this pressure is the argument as to whether time spent or outcomes achieved should be the guiding principal and if time spent, as is currently the case, dominates then there is the uncertainty as to what the ideal number of workplace learning hours is to graduate work ready nurses. Our accrediting body sets the minimum number of workplace learning hours at 800 . We adopted this recommendation for our new program, however we also sought to supplement this with another 240 hours of specific learning opportunities within simulated learning environments. We planned these opportunities to extend further the students' experiences of self organization, adaptation and emergent learning they had begun to experience through their case based inquiries; thus optimizing the quality of the student's subsequent workplace experience. $^{[48,49]}$

The use of simulation as a learning strategy within nursing curricula is widespread due to its capacity to create opportunities for students to be exposed to the complex requirements of clinical events without harm to patients and clients. In doing this, simulation has the capacity to bridge the theory practice gap, improve problem-solving abilities, as well as develop psychomotor and technical skills and improve confidence. ${ }^{[50]}$ In addition, simulated learning environments can be manipulated to present situations to the student that address specific learning objectives contributing to the knowledge, skills, safety and confidence of students. ${ }^{[51]}$

In order to develop authentic simulation learning activities, the simulation team collaborated with other faculty members, registered nurses employed in the healthcare system, healthcare facilities and clinical nurse facilitators (who supervise student nurses whilst on clinical practice). In this way relevant and reliable scenarios can be created to maximize the effect of the simulated learning environment to support the case based inquiries. Creating realism enhances the learning experience and this is achieved through thoughtful development of the simulation scenarios and then ensuring there is

Published by Sciedu Press the capacity and specialized resources to deliver them.

The re-design of the curriculum enabled an extension of the role simulation played in the preparation of our students for work placements, ensuring it was integrated within the case based inquiries and also embedded in the placement units in ways that created the opportunities needed for students to adapt to the complex and unpredictable environments they might find themselves working in. The practical application of these opportunities were built into the design of the course structure and the re-design meant the resources required could be planned for.

\section{RE-DESIGNING THE COURSE STRUCTURE}

Having established our course aim, outcomes, conceptual model and supporting pedagogical framework we were now ready to develop the course structure and content within the confines of the university's prescribed elements. Content was sequenced based on a broadening of knowledge in the first two and half years where foundations in health and professional practice in first year laid the groundwork for complexities in health and illness and holistic nursing practice in years two and three. There could then be a deepening of knowledge in the capstone semester as students transitioned to graduates. This scaffolding of content occurs within the overarching concept of Nursing in a Complex World and the two Domains of People in Health and Illness and Holistic Nursing Practice, as is reflected in our conceptual model (see Figure 2). When examining how the content should be delivered within these domains it was clear that the increasing number of complex health issues and the weighting required to be given to a wide range of health priorities meant that topic or silo type units would not facilitate the outcomes we expected, nor fit with our conceptual approach. ${ }^{[52]}$ As a result, priority areas have been threaded, often in the form of modules, through a number of units over subsequent semesters and years. The initial theory of a topic area is most commonly introduced in units addressing health over the lifespan (Year 1) and then extended and applied in cases within the second and third year acute and community CBI units. One example of this change was our move away from a silo'd content type 'mental health unit' to where the subject is now first introduced during first year in a broad health and human behaviour unit. This foundation is then followed by a module addressing pathophysiology and pharmacology related to mental health conditions in the second year lifespan unit; which, as students' abilities to handle more complex concepts increases, is then further examined through case inquiries and simulations in both acute hospital and community contexts over both semesters in second and third year.

The faculty was keen to ensure simulation, in its many forms, 
was the linchpin for the application of theory to practice, and as such played a key role in the preparation of students for the complex and often unpredictable workplace environment. To that end, simulation was embedded across the two content domains' theory units and within the clinical placement units. Simulated learning was introduced in the theory units in a stepped format from the first year (see Figure 3), where initially opportunities for students to develop essential professional behaviors and psychomotor and communication skills are provided. This beginning offers a strong grounding prior to students undertaking the more complex low and high fidelity simulations in the CBI units, which are delivered across second and third year. The case studies that form the basis for the CBI units are specially designed "individual and family situations" developed to challenge students with a range of nursing problems embedded in simulated real life cases. This is aimed at encouraging students to develop awareness, expertise and confidence in the holistic care of patients and families within changing, uncertain and complex environments. These scenarios were then also carried across into the simulation component of the workplace units.

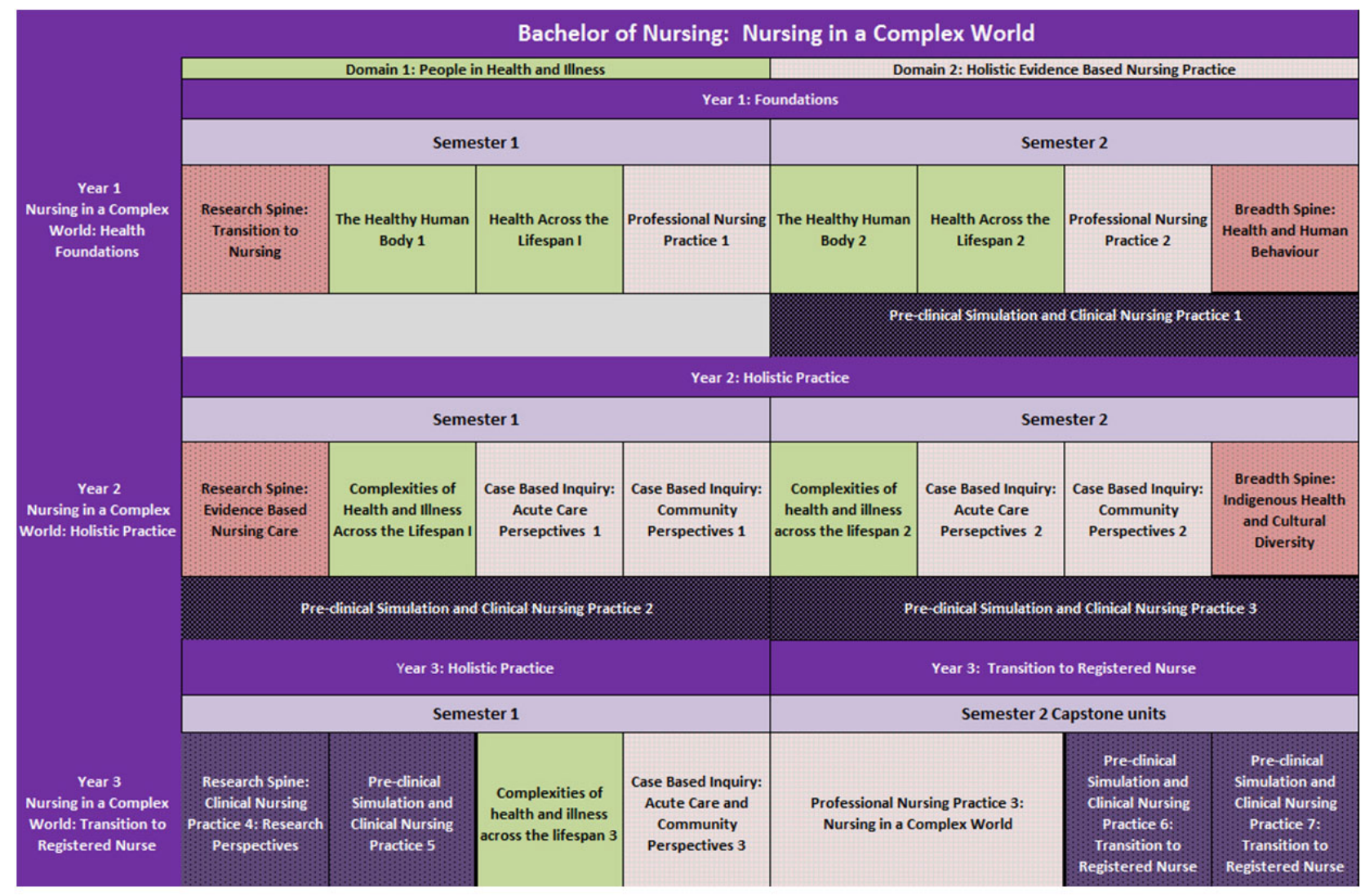

Figure 3. Bachelor of Nursing structure for the new 3 year curriculum: nursing in a complex world

Work Integrated Learning (WIL) units (total 800 hours) were scaffolded across the years to support the major conceptual content domains, complement the case based inquiry units and provide increasing depth of application and competency. Each work integrated learning unit contains an additional period (total 240 hours) of pre-clinical practice placement simulation, specific to the student's clinical placement. During these sessions, students participate in simulated learning scenarios directly applicable to their proposed work placement. For example, if a student is scheduled to attend a mental health clinical placement, the student will complete a pre practicum simulation focused on the mental health needs of the patient/client and the skills required by the student nurse to provide holistic care, no matter the context in which that care may need to be provided. Pre-clinical simulation learning was also augmented by guided reflections completed by students during placement along with attendance at post placement de-briefings. The reflections and post placement de-briefings are conducted by Registered Nurses who supervise students on placement, in conjunction with faculty, providing an opportunity for us to explore the student experience and learnings from the WIL units. Setting aside specific hours in the course structure for this form of preparation, along with the use of clinical practice reflections and post 
placement debriefings, is seen as providing the opportunities the students need to optimize their experiences whilst on placement. ${ }^{[53]}$

The coming together of the final structure and guiding pedagogies for the new curriculum marked for faculty the results of a shared vision brought to fruition through a series of steps, each one carefully planned to inform the next. As a result we felt confident that we could now continue on to the next important stage of preparing for implementation.

\section{BEYOND FIRST STEPS: PREPARATION FOR IMPLEMENTATION AND ASSURANCE OF LEARNING}

While the focus of this paper has been to share the processes and outcomes of the first steps taken in the re-design of our curriculum these beginnings only lay the basis for the work that is to come. That work is now briefly described as an indication of the processes needed to follow through to effect implementation and assurance of learning of the new program. Having developed the aim, outcomes, conceptual model and structure of the degree, expressions of interest were then requested from faculty for unit writers, subject masters and year coordinators to join together to write the units' content for the course with support from the project and simulation teams. This ensured that the shared vision that had occurred in the initial stages of the curriculum redesign continued to be reflected in the content to be delivered during the implementation stage.

During unit development, indicative content was identified and mapped between units throughout the course and against the existing course to ensure constructive alignment. ${ }^{[54]}$ This allowed appropriate distribution of content, development of concepts and levels of complexity to be tailored to unit and course learning outcomes. Indicative content, using key words and concepts, were mapped to Australia's Nursing Competency Assessment Schedule (NCAS), ${ }^{[5]}$ our National Safety and Quality Health Service (NSQHS), ${ }^{[7]}$ and our Registered Nurse Standards for Practice. ${ }^{[8]}$ This process ensures unit content is reflective of professional and industry standards, and any deficient areas can then be identified, reviewed and amended accordingly.

When content was finalized, assessment for learning activities were developed using university policy and guidelines and an assessment guide for unit coordinators was formulated based on Bloom's revised taxonomy. ${ }^{[56]}$ This process was undertaken to ensure assessments complemented one another across units in any given semester and that students were incrementally encouraged to develop their critical thinking and communication skills over the three years of the pro-

Published by Sciedu Press gram. Unit summaries identified how each unit assessment component is then mapped back to unit learning outcomes. The mapping across course content, learning outcomes, assessments, graduate attributes and professional standards within and between units, and across semesters and years allows a clear picture to be formed of how all outcomes will be met. ${ }^{[57]}$ The visualization afforded by mapping also ensures no content areas had been missed, and that individual content areas can be easily located, verified and amended when updating is required, whilst also providing evidence of constructive alignment.

Implementation must be accompanied by evaluation and assurance of learning to ensure the planned outcomes of the program are being met. Currently the program is in its second year of implementation and we are adapting our program evaluation from the five dimensions suggested by Dane $\&$ Schneider. ${ }^{[58]}$ These dimensions include measurement of: how closely actual implementation of the program matches our vision and goals; the quality of the program delivered; the logistics and resource viability of delivering the program as envisioned; student's engagement and satisfaction; the unique contributions it makes to the course outcomes; and the success of the program and subsequent satisfaction of the varying stakeholders. We believe this will result in an environment of iterative, ongoing continuous improvement and stakeholder involvement aimed at closing the evaluation loop and we are confident that our graduates will be well prepared to practice in the ever-changing complex world of nursing

\section{Conclusion}

Designing and implementing a new curriculum carries with it a degree of risk and uncertainty, sometimes requiring an associated leap of faith by faculty. Once the decision to make that leap is taken it requires a rigorous multifaceted approach to align the needs of students, professional and industry stakeholders, university and regulator requirements and community, with faculty's vision for student learning outcomes. We believe that in attending to the processes required to develop a course aim, outcomes and conceptual model to guide the pedagogical underpinnings and structure of our new course, we laid essential groundwork in bringing together a teaching team who were able to create an innovative, relevant and rich offering for our students. The choice of complexity thinking as a guiding theory was key to this groundwork and provided the lens through which we were inspired to graduate nurses with the skills to provide care in complex situations and value the learning that comes through uncertainty, reflection, adaptation and emergence. 


\section{ACKNOWLEDGEMENTS}

We wish to thank all the people both within and outside the organization who so willingly participated in providing feedback and input into the re-design of the curriculum and to all members of the academic team whose vision and enthusiasm for quality nursing education and patient care continues to be a source of reciprocal motivation for us all.

\section{CONFlicts of InTEREST Disclosure}

The authors declare that there is no conflict of interest.

\section{REFERENCES}

[1] Mason M, editor. Complexity theory and the philosophy of education. West Sussex, UK: John Wiley and Sons; 2008. https: //doi.org/10.1002/9781444307351

[2] Bouchaud M, Swan BA, Gerolamo A, et al. Accelerating design and transforming baccalaureate nursing education to foster a culture of health. J Nurs Educ Pract. 2016; 6(11): 97-103. https: //doi.org/10.5430/jnep.v6n11p97

[3] Bouchard M, Brown D, Swan BA. Creating a new education paradigm to prepare nurses fro the 21st century. J Nurs Edu Prac. 2017; 7: 27-35. https://doi.org/10.5430/jnep.v7n10p27

[4] Mitchell GJ, Jonas-Simpson CM, Cross N. Innovative nursing education: interrelating narrative, conceptual learning, reflection, and complexity science. J Nurs Edu Prac. 2013; 3: 30-39. http://doi . org/10.5430/jnep.v3n4p30

[5] Waters CD, Rochester SF, Macmillan MA. Drivers for renewal and reform of contemporary nursing curricula: A blueprint for change. Contemp Nurse. 2014; 41(2): 206-215. http: //doi .org/10.517 2/conu. 2012.41.2.206

[6] Narayan B, Edwards S. Good practice report: Curriculum renewal. Sydney, NSW: Australian Learning and Teaching Council; 2011. Available from: http://eprints.qut.edu.au/50228/1/GPR_C urriculum_renewal_Edwards_(1).pdf

[7] Australian Commission on Safety and Quality in Health Care. National safety and quality health service (NSQHS) standards. Sydney, NSW: ACSQHC; 2012.

[8] Australian Nursing and Midwifery Council. Registered nurse accreditation standards 2012. Canberra, ACT: Australian Nursing and Midwifery Accreditation Council; 2012.

[9] Lachiver G, Tardiff J. Fostering and managing curriculum change and innovation. 32nd Annual Frontiers in Education Conference. IEEE; November, 2002

[10] Tiwari A, Chan S, Law B. Stakeholder involvement in curriculum planning: Responding to healthcare reform. Nurs Edu. 2002; 27: 265-270.

[11] Council of Australian Governments. Health and aging reform agenda. Canberra, ACT: Commonwealth of Australia; 2013.

[12] Daar AS, Singer PA, Persad DL, et al. Grand challenges in chronic non-communicable diseases. Nature. 2007; 450: 494-496. PMid:18033288 https://doi.org/10.1038/450494a

[13] National Health Priority Action Council (AU). National chronic disease strategy. Canberra, ACT: Australian Department of Health and Ageing; 2006. Available from: http://webarchive.nla.g ov.au/gov/20141215061219/http://www.health.gov.au/ internet/main/publishing.nsf/Content/pq-ncds-strat

[14] Nursing and Midwifery Board of Australia. Registered nurse standards for practice. Canberra, ACT: Australian Health Practitioner Regulation Agency; 2016. Available from: http://www.nursingm idwiferyboard.gov.au/Registration-Standards.aspx

[15] Murdoch University. Murdoch university curriculum commission independent steering group academic plan- ning working party curriculum (re) design principles. Perth, WA: Murdoch University; 2013. Available from: https://our.murdoch.edu.au/Staff/MUCC/_document/Gu idelines/AP_ReDesignPrinciples_170913.pdf

[16] Murdoch University. Graduate attributes at Murdoch university. Perth, WA: Murdoch University; 2014. Available from: http://our.murdoch.edu.au/Educational-Development /Preparing-to-teach/Graduate-attributes/

[17] Morrison K. Educational philosophy and the challenge of complexity theory. Educ Theory. 2008; 40(1): 19-33. https://doi.10.1111/ j.1469-5812.2007.00394.x

[18] Plsek PE, Greenhalgh T. The challenge of complexity in health care. BMJ. 2001; 323: 625-628. https://doi.org/10.1136/bmj . 32 3.7313 .625

[19] Wilson T, Holt T. Complexity and clinical care. BMJ. 2001; 323: 685-688. PMid:11566836 https ://doi.org/10.1136/bmj. 323. 7314.685

[20] Plsek PE, Wilson T. Complexity, leadership, and management in healthcare organisations. BMJ. 2001; 323: 746-749. https://doi. org/10.1136/bmj . 323.7315.746

[21] Fraser SW, Greenhalgh T. Coping with complexity: Educating for capability. BMJ. 2001; 323: 799-803. https://doi.org/10.113 $6 / \mathrm{bmj} .323 .7316 .799$

[22] Lindberg CE. Lessons in complexity science: Preparing student nurses for practice in complex health care systems. In Davidson A, Ray M, Turkel M, editors. Nursing, Caring, and Complexity Science: For Human-Environment Well Being. New York, NY: Springer Publishing Company; 2011.

[23] Doll WE, Fleener MJ, Turuit D, et al., editors. Chaos, complexity, curriculum and culture. A conversation. New York, NY: Peter Lang; 2008.

[24] Paley J. The appropriation of complexity theory in health care. J Health Serv Res Policy. 2010; 15: 59-61. PMid:19776331 https: //doi.org/10.1258/jhsrp. 2009.009072

[25] Paley J, Eva G. Complexity theory as an approach to explanation in healthcare: A critical discussion. Int J Nurs Stud. 2011; 48: 269-279. PMid:20956001 https://doi.org/10.1016/j.ijnurstu. 201 0.09 .012

[26] Jorm V, Roberts C. Using complexity theory to guide medical school evaluations. Acad Med. 2017 in press. https://dx.doi.10.1097 /ACM. 0000000000001828

[27] Kannampallil TG, Schauer GF, Cohen T, et al. Considering complexity in healthcare systems. J Biomed Inform. 2011; 44: 943947. PMid:21763459 https://doi.org/10.1016/j.jbi.2011 .06 .006

[28] Townsend GC, Sankey KD. Dynamic systems (complexity) theory as a new conceptual model for researching PBL in dental education. Eur J Dent Educ. 2011; 16: 4 3-51. http://doi.10.1111/j.16 00-0579.2011.00718.x

[29] Jess M, Atencio M, Thorburn M. Complexity Theory: Supporting curriculum and pedagogy developments in Scottish physical educa- 
tion. Sport Educ Soc. 2011; 16: 179-199. http://doi.org/10.1 080/13573322.2011.540424

[30] Jorm C, Nisbet G, Roberts C, et al. Using complexity theory to develop a student-directed interprofessional learning activity for 1220 healthcare students. BMC Med Educ. 2016; 199. https: //doi.org/10.1186/s12909-016-0717-y

[31] Mitchell GJ, Pilkington B, Jonas-Simpson CM, et al. Nursing education and complexity pedagogy: Faculty experiences with an elearning platform. J Nurs Edu Prac. 2016; 6: 60-68. http://doi. org/10.5430/jnep.v6n5p60

[32] James KMG. Incorporating complexity science theory into nursing curricula. Creat Nurs. 2010; 16(3): 137-142. http://doi .org/10 $.1891 / 1078-4535 \cdot 16 \cdot 3.137$

[33] Abraham RH. The genesis of complexity. World Futures. 2011; 67(4-5): 380-394. http://dx.doi:org/10.1080/02604027.2 011.585915

[34] Hidalgo Kehoe M. Complexity theory and nursing: Explanation and application. Holistic Health and Healing 2012. Available from: http://maryannehidalgokehoehhh. wordpress.com/2012 /02/13/complexity-theory-and-nursing-explanation-a nd-application/

[35] Lissack M. Mind your metaphors: Lessons from complexity science. Long Range Plann. 1997; 30(2): 294-298. https://doi: 10.1016/S0024-6301 (96) 00120-3

[36] Skinner BF. The science of learning and the art of teaching. Harv Educ Rev. 1954; 24(2): 86-97.

[37] Knowles MS. Andragogy in action: Applying modern principles of adult education. San Francisco, CA: Jossey-Bass; 1984.

[38] Lebow D. Constructivist values for instructional systems design: Five principles towards a new mindset. Educ Technol Res Dev. 1993; 41(3): 4-16. https://doi.10.1007/BF02297354

[39] Rogers C, Lyon HC, Tausch R. On becoming an effective teacher - person-centered teaching, psychology, philosophy, and dialogues with Carl R. Rogers and Harold Lyon. London, UK: Routledge; 2013.

[40] Gibbs G. Learning by doing: A guide to teaching and learning methods. London, UK: Oxford Centre for Staff and Learning Development Further Education Unit, Oxford Polytechnic; 1988.

[41] Williams B. Case based learning-a review of the literature: Is there scope for this educational paradigm in prehospital education? Emerg Med J. 2005; 22: 577-581. http://doi.10.1136/emj2004.0227 07

[42] Thistlethwaite JE, Davies D, Ekeocha S, et al. The effectiveness of case-based learning in health professional education. A BEME systematic review: BEME guide no. 23. Med Teach. 2012; 34(6): e421-424. http: //doi.org/10.3109/0142159X . 2012.680939

[43] Marton F, Hounsell DJ, Entwhistle NJ, editors. The experience of learning (2nd ed.). Edinburgh, SCT: Scottish Academic Press; 1997.

[44] Feletti G. Inquiry-based and problem-based learning: How similar are these approaches to nursing and medical education? High Educ Res Dev. 1993; 12(2): 143-156. http://doi.org/10.1080/0729 436930120203

[45] Cleverly D. Implementing inquiry based learning in nursing. London, UK: Routledge; 2003.
[46] Council of Deans of Nursing \& Midwifery (AU). Education crisis threatens Federal plans to tackle nursing shortage. Press release. http://www.cdnm.edu.au/assets/nursingplaces08 0318.pdf

[47] Health Professions Education Standing Group (AU). Submission to national commission of audit; 2013. Available from: https://www. universitiesaustralia.edu.au/news/subm issions-and-reports/HPESG-submission-to-National-C ommission-of-Audit\#.V8fCuvmF6Uk

[48] Ferns S, Russell L, Smith C. Designing Work Integrated Learning to optimise student employment readiness. Melbourne, VIC: HERDSA; 2015. Available from: http://www.herdsa.org.au/publicat ions/conference-proceedings/research-and-developme nt-higher-education-learning-life-and-15

[49] Cant RP, Cooper SJ. Simulation based learning in nurse education: Systematic review. J Adv Nurs. 2009; 66(1): 3-15. https: //doi.org/10.1111/j.1365-2648.2009.05240.x

[50] Hope A, Garside J, Prescott S. Re-thinking theory and practice: Pre-Registration student nurses experiences of simulation teaching and learning in the acquisition of clinical skills in preparation for practice. Nurse Educ Today. 2011; 31(7): 711-715. https: //doi.org/10.1016/j.nedt.2010.12.011

[51] McCaughey CS, Traynor MK. The role of simulation in nurse education. Nurse Educ Today. 2010; 30(8): 827-832. https://doi.org/ $10.1016 / j$. nedt .2010 .03 .005

[52] Giddens JF, Brady DP. Rescuing nursing education from content saturation: The case for concept-based curriculum. J Nurs Educ. 2007; 46(2): 65-69. PMid: 17315564

[53] Rystedt H, Sjoblom B. Realism, authenticity, and learning in healthcare simulations: Rules of relevance and irrelevance as interactive achievements. Instr Sci. 2012; 40(5): 785-798. http://doi .10.1 007/s11251-012-9213-x

[54] Biggs J. Aligning teaching and assessing to course objectives. International Conference on Teaching and Learning in Higher Education: New Trends and Innovations. University of Aveiro; April, 2003.

[55] Australian Learning \& Teaching Council, Health Workforce Australia. Nursing competency assessment schedule (NCAS) (version 4.1). Wollongong, NSW: University of Wollongong; 2014.

[56] Anderson LW, Krathwohl DR, editors. A taxonomy for learning, teaching and assessing: A revision of Bloom's taxonomy of education objectives. New York, NY: Longman; 2001.

[57] Lawson R, Taylor T, Herbert J, et al. Hunters and gatherers: Strategies for curriculum mapping and data collection for assuring learning (SP10 -1862) - final report 2013. Sydney, NSW: Office for Learning and Teaching, Department of Industry, Innovation, Science, Research and Tertiary Education; 2013. Available from: http://ro.uow.edu.au/cgi/viewcontent.cgi? article $=1000 \&$ context=hgreport

[58] Dane A, Schneider B. Program integrity in primary and early secondary prevention: Are implementation effects out of control. Clin Psychol Rev. 1998; 18: 23-45. https://doi.org/10.1016/S027 2-7358(97)00043-3 